\title{
F.A.C.E.S. (Faculty Academic Community Education Showcase): Professional Growth Experiences In A Career University
}

Paul J. Colbert, Ph.D., Johnson \& Wales University, USA

\begin{abstract}
Institutes of higher education exist for the purpose of developing, fostering, nurturing, and stimulating the intellectual growth and development of students. The core values of a college education provide students conceptual and practical educational opportunities that focus on improving their skills and knowledge. These skills and knowledge translate into purposeful, reallife learning experiences. However, in the academic community, learning is not restricted to students. Faculty, too, must be supported and provided opportunities for personal and professional growth and development. Although professional development is not a novel concept in the education profession, schools often take up the gauntlet, but fall short of running with it. A commitment to share the collective skills, teaching strategies, and experiences of colleagues in the university community should be one of the institution's core values. The need today for academic rigor and the emphasis on accountability and evidence of professional development of teachers have become key components in faculty performance evaluations in both teaching and research higher educational institutional settings.
\end{abstract}

This paper examines how a career university addresses professional development by embracing change in its faculty orientation process at the start of the academic year through the implementation of a faculty development program and sustainable model for building a teaching and learning showcase of faculty talent. The orientation program - F.A.C.E.S. (Faculty Academic Community Education Showcase) - provides a series of interactive seminars conducted by and for full-time faculty at the Johnson \& Wales University (JWU) Providence, Rhode Island, campus that mirrors their professional expertise, educational best practices, and career experiences within and beyond the JWU academic community. It examines the program goals and objectives, evidence of its evaluation by participants and administration, and the follow-up programs in place to provide further opportunities throughout the academic year that meet faculty needs to learn and engage in a learning environment that translates into and enhances the learning experiences of their students.

Keywords: Faculty Development; Orientation; Best Practices; Teaching Strategies

\section{DISCUSSION}

$\varnothing$ ohnson \& Wales University is a private, non-profit institution with undergraduate and graduate programs in business, hospitality, culinary arts, technology, and education. JWU is a career-focused teaching institution with over 17,000 students on four campuses in Providence, Rhode Island; Miami, Florida; Charlotte, North Carolina; and Denver, Colorado. At the Providence campus alone, the flagship campus, there are over 300 full-time faculty members teaching in the six schools and colleges at both the undergraduate and graduate levels.

Part of the University mission is to provide JWU faculty the professional development opportunities that are focused on teaching and learning in the traditional, blended, and online classrooms. Professional development is integral to the university's strategic plan - Vision 2011 - with one of its vision points clearly focused on enhancing career university 
teaching and teaching skills. These opportunities for development and enhancement of teaching skills and teaching excellence models for faculty use and application are critical to sustained engagement of motivated teachers.

Professional development of faculty is focused on improving the quality of teaching (Weimer, 1990) and has been defined in several ways, toting different handles from leaders in the field, most notably Boyer's model of scholarship that proposed four types of scholarship, primarily focused on research - discovery, integration, application , and SoTL, the scholarship of teaching and learning (1990), as well as Weimer's instructional or faculty development that addresses how institutions can customize programs to improve faculty teaching (1990). In his attempt to classify works in the field of professional development, Potter (2011) refers to Weimer's handle of SoTL as pedagogical research. It is recognized as a practice that draws on the works and findings of scholar-practitioners and varies from one school to the next, primarily on each institution's core values with respect to teaching and learning and the needs of its faculty.

As a member of POD - the Professional and Organizational Development Network in Higher Education (http://www.podnetwork.org/index.htm) - a support organization consisting of faculty, staff, and administration members, primarily from the U.S. and Canada and with membership representation in over 20 other countries, we are "change agents" (http://www.pdnetwork.org/membership.htm) in professional/faculty development . A primary goal of the organization is to provide opportunities for members to share their teachings and where faculty development is not viewed as a remedial fix, but rather as an enhancement of existing teaching styles and best practices. It is through this series of connections for faculty to collaborate with their colleagues and share ideas, perspectives, and strategies that benefit faculty, students, and university communities that recognize how the university might spotlight teaching talent and showcase it.

\section{PROGRAM OVERVIEW}

A unique way to provide best practices and showcase excellence in teaching for our Providence faculty was to avail them with collaborative opportunities at the right time - at faculty orientation, the annual mandatory meeting for all full-time faculty held each academic year before classes commence. It is the one time of the year that all faculty convene in one area on campus for the common goal of renewing their commitment to excellence in teaching. F.A.C.E.S. (Faculty Academic Community Education Showcase) was designed as the vehicle through which we could celebrate this renewal by providing faculty a forum for exchanging and sharing teaching practices and ideas, a networking exchange with colleagues beyond the confines of individual departments and schools, and a more personalized means of celebrating commitment to excellence. It is comprised of a community of academicians whose colleagues share their best practices for teaching and learning, classroom management techniques and active learning environments, educational professionals who gather to talk teaching and learning, showcase good teaching, and share resources and materials.

F.A.C.E.S. is perceived as a reward system for good teaching, a vehicle encouraging innovation and collaboration, providing the JWU community-at-large with the following benefits:

- $\quad$ Enhanced teaching and learning for faculty at all ranks

- $\quad$ Program developed for and by faculty sharing best practices

- $\quad$ Networking and collaborating opportunities not readily present during the academic year due to teaching schedules and administrative responsibilities

- Workshop-seminar take-aways - options for teaching that have been tested by fellow colleagues in an urban, career-focused university setting boasting a large population of international students

- $\quad$ Behavioral motivators to sustain engagement in a new academic year

- $\quad$ Catalyst for additional follow-up program offerings during the academic year

- Integral component of the university academic culture and community

With a significant population of international students, JWU is committed to its mission to prepare its diverse student body for career-focused educational opportunities. Table 1 shows the steady increase in international students attending the university at both the undergraduate and graduate levels, specifically with an overall campus population of Chinese students representing $7 \%$ of registered full-time students and $30 \%$ of the graduate school population. This has presented significant challenges to faculty in meeting the needs of such a diverse population while maintaining academic rigor (Colbert, 2010). F.A.C.E.S. provides a unique opportunity to tap into faculty to share their multicultural classroom teaching practices with their colleagues across campus, as well as establish a 
forum for international students to share, with faculty, their expectations and experiences in the U.S. higher education classroom.

Table 1: JWU International Population (2006-2010)

\begin{tabular}{lrr} 
& $\mathbf{2 0 0 6}$ & $\mathbf{2 0 1 0}$ \\
UG & 535 & 973 \\
GradESL & 27 & 93 \\
MBA & 438 & 639 \\
Totals & 1000 & 1705 \\
\hline Over 7\% Providence Campus = International = Chinese \\
\hline Over \$10 M tuition revenue \\
30\% Graduate School Population \\
\hline 24\% COB-Financial Services
\end{tabular}

The F.A.C.E.S. planning process is rigorous and commences during the previous winter and spring academic terms. The program requires strong administrative support and recognition by the Office of Academic Affairs and the deans of each school and college who sponsor the program and assist in the final selection process of faculty facilitators. Via an online survey process, all full-time faculty members are invited to: 1) identify specific topics or areas of interest that are focused on teaching and learning that they would like to see offered and 2) participate in and/or lead one of the seminars individually or with a colleague(s).

The facilitator selection process is a cross-representation of Providence full-time faculty members who demonstrate enthusiasm for teaching and an interest in sharing their classroom experiences and practices with their colleagues. The general theme of the orientation program is Teaching Excellence and a variety of topics (that "hook" faculty) was selected to motivate interest in extending the program with similar offerings, beyond orientation, throughout the academic year. Interested faculty members are invited to submit a proposal focused on their best practices in teaching and learning. In addition faculty facilitators are nominated by colleagues, deans and department chairs of each school and college on the Providence campus, as well as from testimonials submitted by fellow colleagues who recognize individual teaching expertise. Based on the initial preliminary survey results sent to all faculty in the spring, the author met with interested faculty members, staff, and faculty who were recommended by administrators and/or colleagues, representing all six schools and colleges on the Providence campus, to design and develop a series of seminars $(n=13)$. This was then presented in July in menu format in an online registration form to full-time faculty ( $\mathrm{n}=306$ current and newly-hired faculty) for them to select from the options provided and complete the registration requirements by the first part of August.

In the F.A.C.E.S. program, each full-time faculty member is required to attend two 90 -minute sessions. A cap of 25 participants in each seminar allows for more interactivity which requires that faculty be assigned to their seminar choices on a first-come, first-serve basis. For the 2010-2011 orientation, faculty were asked to prioritize three choices for each of the two-time sessions within a given deadline for submission. Once the registration was received, each faculty member was assigned to seminars based on availability of his/her first, second, and/or third choices. Faculty members who had not submitted their preferences were subsequently assigned to available seminars. Upon arriving at the orientation, all faculty members were provided a program brochure identifying faculty by name with the times and room/lab locations for the two seminars for which they were registered. 
The 13 seminars were categorized as follows:

$\circ \quad$ Academic (teaching and learning)

- Seminar 2: Experiential education (integrating into the classroom)

- Seminar 3: Brain-based learning (best teaching practices)

- Seminar 4: Behavioral motivators (triggering internal motivators)

- Seminar 5: Cross-discipline design (collaboratives)

- Seminar 6: Dazzle and demonstrate (enhancing student presentations)

- Seminar 7: Disruptive behaviors (classroom management)

- Seminar 8: Faculty collaboration (team teaching)

- Seminar 9: International classrooms at JWU (student panel)

- Seminar 10: Making the grade - writing across disciplines

○ Professional Development

- Seminar 1: Terminal degree while teaching

$\circ \quad$ Teaching with Technology

- Seminar 11: F.A.C.T.S. - Faculty Academic Course Technology Strategies

- Seminar 12: Digital natives (learning behaviors of digital natives)

- Seminar 13: Visual pedagogy - Reimagining the power of PowerPoint

\section{PROGRAM EVALUATION}

The 15 questions measuring faculty satisfaction were coded as shown in Table 2.

Table 2: Measurement of Faculty Satisfaction

\begin{tabular}{|l|ll|}
\hline Variable Code & \multicolumn{2}{|c|}{ Variable Description } \\
\hline Goals & 1. & The goals of the seminar were clearly defined \\
\hline Relev & 2. & The topics covered were relevant \\
\hline Value & 3. & The content was valuable to my teaching goals \\
\hline Interact & $4 . \quad$ There was sufficient opportunity for interactive participation \\
\hline Tech & $5 . \quad$ The content presented was too technical to fully understand \\
\hline Use & $6 . \quad$ The experience can be effective in my classroom \\
\hline Questn & $7 . \quad$ Most questions were answered during the seminar \\
\hline Matls & $8 . \quad$ The materials used in the seminar were helpful \\
\hline Activity & $9 . \quad$ The seminar covered the proposed activities \\
\hline Handout & 10. & The handouts provided were helpful \\
\hline Particip & 11. & Active participation was encouraged \\
\hline Approp & 12. & The content was appropriate for any discipline at any level \\
\hline Comfort & 13. & The meeting room provided a comfortable setting \\
\hline Equip & 14. & The tools and equipment used during the seminar worked well \\
\hline Time & 15. & The amount of time provided allowed participants a basic understanding of the topic \\
\hline
\end{tabular}

The survey questionnaire results measured faculty perceptions of the F.A.C.E.S. orientation program seminars $(\mathrm{n}=13)$ held during the Fall 2010 orientation. The assessment was intended to evaluate the program offerings in terms of meeting faculty goals in enhancing teaching, relevancy of the topics to JWU classroom teaching and learning, interactivity, handouts and materials, environment and time allotted. It was not intended to be an evaluation of facilitator performance. The objective was to gather faculty members' expectations of and experiences with the two required seminars they attended, with the expectation that this would serve as a catalyst and possible deciding factor of the focus and direction of intended future program offerings for the upcoming academic year. 
The overall mean results of the 15 questions for individual seminars conducted are presented in Table 3 with highlighted results of specific seminars for clearly defined goals, relevant topics, value to teaching goals, and appropriateness for any discipline area(s). Faculty "agreed to strongly agreed" $(\mathrm{x}=4.35)$ that the goals of Seminars 1-7 (terminal degrees, experiential education, brain-based learning, behavioral motivators, cross-discipline curriculum design, dazzle and demonstrate presentations, and disruptive behaviors), 9-10 (International classrooms at JWU and writing across disciplines), and 13 (visual pedagogy) were clearly defined and somewhat agreed that they were reached in seminars 8 (team teaching), 11 (academic technology strategies), and 12 (digital natives). Faculty strongly agreed that terminal degree programs $(x=4.71)$, behavioral motivators $(x=4.77)$, disruptive behaviors ( $x=4.67)$, writing across disciplines $(x=4.70)$, and visual pedagogy (4.73) met defined goals.

Overall, participants "agreed to strongly agreed $(x=4.34)$ " that the topics covered were relevant, highlighting that terminal degree $(x=4.71)$, behavioral motivators $(x=4.85)$, disruptive behaviors $(x=4.67)$, writing across disciplines $(x=4.70)$, and visual pedagogy $(x=4.79)$ seminars specifically met their needs. The majority of faculty also found that the seminars added value to their specific teaching goals $(x=4.02)$ with emphasis on behavioral motivators $(\mathrm{x}=4.69)$, disruptive behaviors $(\mathrm{x}=4.63)$, and visual pedagogy $(4.70)$.

The results also indicated that the respondents "agreed to strongly agreed" that the seminar was appropriate for any discipline at any level $(\mathrm{x}=4.02)$ with particular emphasis on behavioral motivators $(\mathrm{x}=4.73)$ and disruptive classroom behavior $(\mathrm{x}=4.67)$.

The overall program mean results in Table 4 suggested that $85 \%$ of the respondents $(x=4.01)$ "agreed to strongly agreed" that the goals of the seminars were met, while $84 \%(\mathrm{x}=4.01)$ indicated they were satisfied with the F.A.C.E.S. program offerings. The majority of faculty perceived that the seminars increased their understanding of the topics, specifically those that provided opportunities to use the content in their teaching $(84 \%, x=3.99)$. Over $70 \%(x=3.76)$ of the respondents plan to share the information with colleagues in their departments and schools. This rating is the result of a number of culinary arts (CCA) faculty who teach in lab settings and indicated that they have less opportunity to apply these practices in their class-lab environments; and who also expressed interest in attending in-services/seminars focused more on their specific curriculum. Although F.A.C.E.S. is designed to accommodate a heterogeneous mix of faculty through best practices and each school or college generally provides individual in-service opportunities for their instructors, the program strives to obtain representation from each school in sharing their teaching practices with colleagues. For the 2011-12 orientation (cancelled due to Hurricane Irene), there were additional CCA instructors scheduled to participate as program facilitators and who would be providing seminars during the 2011-2012 winter and spring terms.

Table 3: Overall Mean Results by Seminar

[Scale: 1 = Totally disagree; $2=$ Disagree; $3=$ Neither agree/disagree; $4=$ Agree; $5=$ Strongly agree

\begin{tabular}{|c|c|c|c|c|c|c|c|c|c|c|c|c|c|c|c|}
\hline & 1 & 2 & 3 & 4 & 5 & 6 & 7 & 8 & 9 & 10 & 11 & 12 & 13 & 14 & 15 \\
\hline Sem & Goals & Relev & Value & Interact & Tech & Use & Questn & Mat'ls & Activity & Handout & Particip & Approp & Comfort & Equip & Time \\
\hline 1 & 4.71 & 4.71 & 3.47 & 4.47 & 2.47 & 2.00 & 4.41 & 4.59 & 4.12 & 4.71 & 4.59 & 3.35 & 3.88 & 3.82 & 4.76 \\
\hline 2 & 4.00 & 3.76 & 3.82 & 3.82 & 2.12 & 3.41 & 3.94 & 3.71 & 4.00 & 3.00 & 3.94 & 3.94 & 3.88 & 3.18 & 4.12 \\
\hline 3 & 4.57 & 4.46 & 4.20 & 4.51 & 1.91 & 4.23 & 4.26 & 4.23 & 4.17 & 4.00 & 4.23 & 4.17 & 3.83 & 4.20 & 4.29 \\
\hline 4 & 4.77 & 4.85 & 4.69 & 4.27 & 2.58 & 4.54 & 4.42 & 4.58 & 4.42 & 4.38 & 4.35 & 4.73 & 4.38 & 4.65 & 4.12 \\
\hline 5 & 4.11 & 3.89 & 3.16 & 3.79 & 1.84 & 2.63 & 3.89 & 3.37 & 3.84 & 2.79 & 4.26 & 3.89 & 3.74 & 4.00 & 4.00 \\
\hline 6 & 4.48 & 4.32 & 4.04 & 4.68 & 1.72 & 3.84 & 4.24 & 3.84 & 4.40 & 1.92 & 4.20 & 3.68 & 4.24 & 4.60 & 4.44 \\
\hline 7 & 4.67 & 4.67 & 4.63 & 4.63 & 1.93 & 4.50 & 4.47 & 4.03 & 4.60 & 2.60 & 4.73 & 4.67 & 4.33 & 4.43 & 4.43 \\
\hline 8 & 3.94 & 3.82 & 3.41 & 3.76 & 1.35 & 3.00 & 3.41 & 3.00 & 3.76 & 3.06 & 3.94 & 3.71 & 3.82 & 2.71 & 3.82 \\
\hline 9 & 4.41 & 4.41 & 4.26 & 4.44 & 1.56 & 4.11 & 4.15 & 3.07 & 4.07 & 2.37 & 4.19 & 4.11 & 4.00 & 3.30 & 3.93 \\
\hline 10 & 4.70 & 4.70 & 4.40 & 4.40 & 1.80 & 4.30 & 4.60 & 4.30 & 4.50 & 4.40 & 4.80 & 4.60 & 4.10 & 4.00 & 4.30 \\
\hline 11 & 3.88 & 4.16 & 3.84 & 3.53 & 2.88 & 3.81 & 3.94 & 3.88 & 4.06 & 3.31 & 3.88 & 3.69 & 4.06 & 4.22 & 3.88 \\
\hline 12 & 3.64 & 3.91 & 3.68 & 3.77 & 2.09 & 3.59 & 3.73 & 3.64 & 3.68 & 2.73 & 3.82 & 3.41 & 3.82 & 3.68 & 3.68 \\
\hline 13 & 4.73 & 4.79 & 4.70 & 4.21 & 2.12 & 4.61 & 4.55 & 4.64 & 4.61 & 4.73 & 3.61 & 4.36 & 4.03 & 4.33 & 4.48 \\
\hline $\mathrm{Av}$ & 4.35 & 4.34 & 4.02 & 4.18 & 2.03 & 3.74 & 4.15 & 3.91 & 4.17 & 3.38 & 4.20 & 4.02 & 4.01 & 3.93 & 4.17 \\
\hline
\end{tabular}


Table 4: Mean Results - Overall Program Assessment

[Scale: $1=$ Totally disagree; $2=$ Disagree; $3=$ Neither agree/disagree; $4=$ Agree; $5=$ Strongly agree

\begin{tabular}{|l|c|c|c|c|c|c|c|}
\hline & $\begin{array}{c}\text { Strongly } \\
\text { disagree }\end{array}$ & Disagree & $\begin{array}{c}\text { Neither } \\
\text { agree/disagree }\end{array}$ & Agree & $\begin{array}{c}\text { Strongly } \\
\text { agree }\end{array}$ & $\begin{array}{c}\text { Rating } \\
\text { average }\end{array}$ & $\begin{array}{c}\text { Response } \\
\text { count }\end{array}$ \\
\hline $\begin{array}{l}\text { The goals of the seminars } \\
\text { have been met }\end{array}$ & $1.4 \%(2)$ & $2.7 \%(4)$ & $10.8 \%(16)$ & $\begin{array}{c}\mathbf{6 3 . 5 \%} \\
(\mathbf{9 4})\end{array}$ & $\begin{array}{c}21.6 \% \\
(32)\end{array}$ & $\mathbf{4 . 0 1}$ & 148 \\
\hline $\begin{array}{l}\text { I am satisfied with my } \\
\text { increased understanding of } \\
\text { the topics }\end{array}$ & $2.0 \%(3)$ & $\begin{array}{c}6.8 \% \\
(10)\end{array}$ & $8.8 \%(13)$ & $\begin{array}{c}62.8 \% \\
(93)\end{array}$ & $\begin{array}{c}19.6 \% \\
(29)\end{array}$ & 3.91 & 148 \\
\hline $\begin{array}{l}\text { I intend to make use of the } \\
\text { content provided in my } \\
\text { teaching }\end{array}$ & $2.0 \%(3)$ & $2.7 \%(4)$ & $11.5 \%(17)$ & $\begin{array}{c}62.2 \% \\
(92)\end{array}$ & $21.6 \%$ & 3.99 & 148 \\
\hline $\begin{array}{l}\text { I plan to share the } \\
\text { information I received with } \\
\text { my colleagues }\end{array}$ & $2.0 \%(3)$ & $6.1 \%(9)$ & $22.3 \%(33)$ & $\begin{array}{c}\mathbf{5 3 . 4 \%} \\
(\mathbf{7 9})\end{array}$ & $\begin{array}{c}16.2 \% \\
(24)\end{array}$ & $\mathbf{3 . 7 6}$ & 148 \\
\hline $\begin{array}{l}\text { The program provided me an } \\
\text { opportunity to meet other } \\
\text { faculty from different } \\
\text { disciplines and backgrounds }\end{array}$ & $2.1 \%(3)$ & $4.1 \%(6)$ & $11.6 \%(17)$ & $\begin{array}{c}52.1 \% \\
(76)\end{array}$ & $\begin{array}{c}30.1 \% \\
(44)\end{array}$ & 4.04 & 146 \\
\hline $\begin{array}{l}\text { Overall, I was satisfied with } \\
\text { the professional development } \\
\text { offerings }\end{array}$ & $2.0 \%(3)$ & $6.1 \%(9)$ & $7.4 \%(11)$ & $\begin{array}{c}\mathbf{5 7 . 4 \%} \\
(\mathbf{8 5})\end{array}$ & $27.0 \%$ & $\mathbf{4}$ \\
\hline
\end{tabular}

Each of the six schools and colleges on the Providence campus was represented at orientation. As indicated in Table 5, total attendance at the program $(n=266)$ included Arts \& Sciences (A\&S), College of Culinary Arts (CCA), College of Business (COB), Graduate School (Grad), Hospitality College (Hosp), School of Education (SOE - now part of Graduate School), and the School of Technology (SofT). One hundred forty-eight ( $\mathrm{n}=148$ ) or 56\% of the faculty in attendance completed the program assessment, represented by $60 \%$ of the A\&S faculty, $47 \%$ Culinary Arts, $62 \%$ College of Business, $80 \%$ of the Graduate faculty, $52 \%$ of the Hospitality College, $38 \%$ of the School of Education, and $62 \%$ of the School of Technology.

Table 5: Mean Results - Overall Program Assessment by School/College

[1 = Totally disagree; 2 = Disagree; 3 = Neither agree/disagree; 4 = Agree; 5 = Strongly agree $]$

\begin{tabular}{|l|c|c|c|c|c|c|c|c|c|}
\hline & $\begin{array}{c}\text { Rec'd } \\
\text { /Sent }\end{array}$ & $\begin{array}{c}\text { Goals } \\
\text { (A) }\end{array}$ & $\begin{array}{c}\text { Satisfied } \\
(\mathrm{B})\end{array}$ & $\begin{array}{c}\text { Use } \\
(\mathrm{C})\end{array}$ & $\begin{array}{c}\text { Share } \\
(\mathrm{D})\end{array}$ & $\begin{array}{c}\text { Meet } \\
(\mathrm{E})\end{array}$ & $\begin{array}{c}\text { Prof } \\
\text { Dev (F) }\end{array}$ & $\begin{array}{c}\text { Attend } \\
(\mathrm{G})\end{array}$ \\
\hline A\&S & $43 / 72$ & 4.12 & 3.98 & 4.16 & 3.77 & 4.16 & 4.00 & $88 \%$ \\
\hline CCA & $37 / 79$ & 4.08 & 4.03 & 3.95 & 3.76 & 4.22 & 3.97 & $76 \%$ \\
\hline COB & $29 / 47$ & 3.97 & 3.72 & 3.79 & 3.66 & 3.86 & 3.97 & $97 \%$ \\
\hline Grad & $8 / 10$ & 4.13 & 4.13 & 4.00 & 3.88 & 4.13 & 4.13 & $75 \%$ \\
\hline Hosp & $15 / 29$ & 3.87 & 4.20 & 4.13 & 3.93 & 4.07 & 4.27 & $93 \%$ \\
\hline SOE & $3 / 8$ & 4.00 & 4.00 & 4.33 & 4.00 & 4.00 & 4.00 & $100 \%$ \\
\hline Soft & $13 / 21$ & 4.00 & 3.62 & 4.00 & 3.92 & 3.85 & 3.92 & $92 \%$ \\
\hline Total & $148 / 266$ & 4.01 & 3.91 & 3.99 & 3.76 & 4.04 & 4.01 & $87 \%$ \\
\hline
\end{tabular}

(A) The goals of the seminars have been met

(B) I am satisfied with my increasing understanding of the topic

(C) I intend to make use of the contents provided in my teaching

(D) I plan to share the information I receive with my colleagues

(E) The program provided an opportunity to meet/work with faculty

(F) Overall I was satisfied with the professional development offerings

(G) I would attend F.A.C.E.S. seminars if offered during the academic year 
Overall, each school or college agreed that the program met their professional development expectations [Table 5, (F)] and they would make use of the content provided in the seminars (C), as well as plan to share the information with colleagues (D) $(x=3.99$ to 4.01$)$. Being able to work and dialogue with other faculty (E) $(x=4.04)$ was perceived as an important component of the program. Of the 148 who responded, $87 \%$ indicated that they would attend F.A.C.E.S. seminars (G) if offered during the academic year. With $47 \%$ of the Culinary faculty who attended the seminars completing the assessment, only $76 \%$ indicated they would attend seminars during the year. This is due primarily to rigid teaching schedules 5-6 days per week.

Participants were also asked to respond to the following two open-ended questions:

1. What would you do differently in your classes based on attending this seminar?

2. How would you enhance this seminar?

Recognizing that F.A.C.E.S. is a vehicle designed to spark faculty interest in expanding their practices and rejuvenating their teaching, faculty responded to what they would do differently in their classes based on attending F.A.C.E.S. indicating that it was important for them to: 1) better assess the learning styles of their students in class and 2) reassess their teaching of international students, which they perceived needed more focus and an awareness of cultural differences. In summary, they indicated that they would attempt to make more use of teaching aids and materials that were provided in the seminars and offer more real-world experiences. A number of faculty indicated that they would welcome working with their colleagues more in collaborative efforts across disciplines, where appropriate. Other faculty are seeking technical assistance to infuse technology more in their classrooms after attending the Teaching with Technology seminars.

In response to how they would enhance the seminars they attended, respondents overwhelmingly recommended that there be further in-services in technology and that the program expand the facilitator base to demonstrate equitable distribution among the facilitators. Representation consisted of A\&S School faculty (8), College of Culinary Arts (2), College of Business (2), Graduate School (1), Hospitality College (3), and staff from the International Center, Academic Technology, and the Dean of Library Services (4). An examination of faculty who respond to working as facilitators in F.A.C.E.S. shows an overwhelming response from Arts \& Sciences and an increasing number from the Colleges of Business and Culinary Arts. The emphasis is to increase efforts to reach a different mix of facilitators and encourage members of all schools and colleges to more readily share their teaching expertise with their colleagues.

Respondents also recommended increased time frames to allow for more interaction in the seminars and that facilitators bring more examples and allow more time to share them. This presents a challenge since F.A.C.E.S. is but one component of the orientation program which also includes a welcoming address by administration, luncheon, and a separate orientation for new faculty all held the same day. Our F.A.C.E.S. time frame is currently limited to three hours. The solution was to provide these seminars throughout the academic year to enable follow-up and/or beginning sessions with selected seminars. Faculty would be allowed to use these seminars to meet their inservice requirements (6 hours) as well as use them as contributing to points for academic rank promotion with the University Committee on Academic Rank (UCAR) requirements. This, however, does present timing and scheduling issues making it unsuitable for a number of faculty, particularly CCA, whose teaching schedules are inflexible to meet during late afternoon time periods and/or Friday morning and afternoon when there are fewer classes being held.

Facilitators were also requested to self-evaluate their content and delivery to determine their perceptions of their audiences which were a mix of faculty who registered for their seminars and those who were scheduled into seminars based on non-responses to the survey questionnaire or not meeting the deadline for submission. This required placing faculty into seminars that might not have been their choices had they submitted their requests on time. Descriptions of the seminars were provided, but they were not identified by facilitator names in order to avoid bias in attending sessions conducted by colleagues or individuals with whom they share a professional relationship.

The facilitators, in general, felt that they needed to pace their delivery and content to adjust to the time frame of 90 minutes, as a number of them either did not have the opportunity to provide specific elements or allocate 
planned activities more efficiently. They indicated that they would like to enhance interactivity while being able to cover all major points. It was evident that in a number of seminars, more examples that were appropriate for all schools and colleges are required to maintain interest. Overall, facilitators would be willing to repeat their offerings throughout the academic year and prep a follow-up session to the introductory session, where applicable.

\section{CONCLUSION}

The general commentary from faculty regarding F.A.C.E.S., as a delivery system of professional development or growth opportunities, illustrated enthusiasm and interest in having F.A.C.E.S. as an annual event. Although there were suggestions to have the program in June before the summer and a new academic year, it would present challenges to offer it as a required campus event. A number of faculty are involved in study abroad programs or are traveling and/or attending conferences during the period June through August. Fall orientation is the one time during the academic year that all full-time faculty are required to attend, and most return to campus with a sense of renewal and a high level of enthusiasm. It is at this time that participants more fully recognize the need to reach across disciplines and work with their colleagues in sharing ways to meet the needs of the JWU student. The program quickly became the initial boost to the academic year and sparked motivation for faculty to focus on engaging students more in their classrooms and enhancing their classroom experiences.

Participants were receptive to an interactive orientation program where they had an opportunity to observe and engage in what their colleagues are doing in the classroom, across schools and disciplines, at both the undergraduate and graduate levels. Evidence from the questionnaire results clearly suggested that most faculty, based on scheduling and availability, would welcome the opportunity to attend follow-up and/or additional seminars in which they were interested. This indicated that the program objective - for further sustained engagement in professional development opportunities during the academic year for faculty - was achieved.

As a result, the F.A.C.E.S. program was extended throughout the academic year with a selection of orientation program offerings for 2010-2011. Based on facilitator input and their self-evaluation results from the orientation program, the facilitators updated, revised or revamped their materials for these additional seminars for the 2011-2012 fall, winter, and spring terms. In anticipation of the 2011-2012 orientation, the program included other faculty who expressed an interest in participating in F.A.C.E.S. and who were invited to submit proposals. Several of the original 2010-2011 seminars were brought back by popular demand, at both the basic and advanced levels, as well as additional seminars expressly focused on international students and cultural differences in the classroom at both the undergraduate and graduate levels.

The program highlights and showcases faculty talent that continues to impress colleagues across the Providence campus schools and colleges, pointing to the need to sustain faculty engagement in professional growth opportunities (that are provided by and for faculty) across campus. As one participant put it, "the more we are exposed to these types of opportunities, the better the chances are that we will become better teachers."

\section{AUTHOR INFORMATION}

Dr. Paul J. Colbert is a faculty member at Johnson \& Wales University, Providence, RI where he is a professor of Research in the MBA program. He serves as Chair, Faculty Professional Development and was formerly the Director, Center for Teaching Excellence designing programs in teaching and learning and use and application of educational technologies. His research interests include active learning in higher education and its impact on the scholarship of teaching and learning. E-mail: Paul.Colbert@jwu.edu.

\section{REFERENCES}

1. Boyer, E.L. (1990). Scholarship reconsidered: Priorities of the professoriate. Princeton, NJ: Princeton University Press, The Carnegie Foundation for the Advancement of Teaching.

2. Colbert, P.J. (2010). Developing a culturally responsive classroom collaborative of faculty, students and institution. Journal of College Teaching \& Learning, 7(11), 15-24. 
3. Potter, M. (2011). Toward a scholarship of faculty development. In Miller, J.E., \& Groccia, J.E. (Eds). To improve the academy (288-301). San Francisco: John Wiley \& Sons, Inc.

4. Weimer, M. (1990). Improving college teaching. San Francisco: Jossey-Bass, Inc. 
NOTES 